\title{
A extensão universitária e o futuro da universidade
}

\author{
The extension and the future of the university
}

\author{
Sandra de Fátima Batista de Deus* \\ A falta de humildade, [sic] se expressa na arrogância e na \\ falsa superioridade de uma pessoa sobre a outra, de uma \\ raça sobre a outra, de um gênero sobre o outro, de uma \\ classe ou de uma cultura sobre a outra, é uma transgressão \\ da vocação humana do ser mais (FREIRE, 1997, p. 137).
}

\section{Resumo}

Este estudo propõe uma reflexão sobre o papel da extensão universitária no futuro da universidade brasileira. Para tanto, considera-se que este caminho deve ser pautado pela reflexão em torno dos 100 anos da Reforma de Córdoba, pelos encaminhamentos da Conferência Regional de Educação Superior, pela urgente necessidade de defesa da universidade pública, pela incorporação da Agenda 2030 na pauta da extensão universitária e, muito especialmente, por três componentes que marcam a contradição interna das universidades: os currículos engessados; o acomodamento/desencanto docente e discente e a estrutura universitária distante e com poucas condições de atender as demandas da sociedade. A universidade pública, que cumpre um papel fundamental na sociedade brasileira, tem sido questionada em todos os sentidos. Um questionamento que tem como finalidade o desmonte do ensino público e gratuito e que está calcado na total ignorância sobre o desempenho destas instituições. A extensão universitária tem tarefas importantes a cumprir nestes períodos de turbulência e definição de novas rotas.

Palavras-chave: Agenda 2030. Cidadania. Compromisso social. Desmonte da universidade. Extensão universitária.

\section{Abstract}

The purpose is a reflection of the role of the university extension in the future of Brazilian universities. In order to do so, we consider that this path must be guided by the reflection of the 100 Years of the Reform of Cordoba, the referrals of the Regional Conference on Higher Education, the urgent need to defend the public university, the incorporating the Agenda 2030 in the discussion of university extension and, mainly, by three components that mark the internal condition of the universities: the embedded curricula; the professors/students disenchantment and accommodation; and the distant university structure, with few conditions to meet the demands of the society. The public university, which plays a fundamental role in the Brazilian society, has been questioned in every way. A questioning that has the objective to dismantle the free public education, and which is based on total ignorance about the performance of these institutions. The university extension has important tasks to fulfill in these periods of turbulence and definition of new routes.

Keywords: Agenda 2030. Citizenship. Dismantle of the university. Social commitment. University extension.

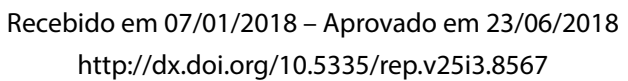

Doutora em Comunicação e Informação (UFRGS). Jornalista. Professora associada da Faculdade de Biblioteconomia e Comunicação da Universidade Federal do Rio Grande do Sul (UFRGS). Pró-Reitora de Extensão da UFRGS. E-mail: sdeus@terra.com.br 
A Constituição brasileira de 1988 estabeleceu a "indissociabilidade entre ensino, pesquisa e extensão" e definiu que "as atividades universitárias de pesquisa e extensão poderiam receber apoio financeiro do poder público" (BRASIL, 1988). A partir da década de 1990, a institucionalização da extensão foi marcada por diferentes encaminhamentos, como: o Programa de Fomento à Extensão Universitária (Proext), em 1993; a Lei de Diretrizes e Bases da Educação Nacional (LDB), em 1996, que estabelece a extensão universitária como uma das finalidades da universidade e institui a possibilidade de apoio financeiro do Poder Público, inclusive mediante bolsas de estudo; o Plano Nacional de Extensão em 1998; o Plano Nacional de Educação (PNE) em 2001, que estabelece a responsabilidade das universidades nas suas funções de ensino, pesquisa e extensão, na formação inicial e continuada dos profissionais da educação básica; o novo PNE em 2014, que estabelece e reforça metas e estratégias que envolvem a educação no contexto brasileiro para o período de 2014-2024. Entre essas metas, destaca-se a de número 12.7: "Assegurar, no mínimo, $10 \%$ do total de créditos curriculares exigidos para a graduação em programas e projetos de extensão universitária, orientando sua ação, prioritariamente, para áreas de grande pertinência social" (BRASIL, 2014).

A extensão universitária como relação da universidade com a sociedade se constitui na oxigenação da própria universidade, na democratização do conhecimento acadêmico, na incorporação de saberes. É uma "interação dialógica" que traz múltiplas possibilidades de transformação da sociedade e da própria universidade pública (FORPROEX, 2012). Em 2012, após debates internos nos encontros do Fórum de Pró-Reitores de Extensão de 2009 e 2010, foi definido um novo conceito de extensão: "um processo interdisciplinar, educativo, cultural, científico e político que promove a interação transformadora entre Universidade e outros setores da sociedade" (FORPROEX, 2012, p. 42).

Portanto, os instrumentos legais e resolutivos no interior das universidades estão calcados na formação universitária em um eixo com três pontas. O propagado tripé acadêmico é responsável pela formação em todas as áreas do conhecimento com atuação na pesquisa e nas ações da comunidade. Rodriguez entende que docência, investigação e vinculação com o meio fundamentam "o sentido de las universidades completas e complejas" (2016, p. 19). É evidente que, em situações das mais variadas, ora por força de uma carga horária elevada dentro da sala de aula, ora por comodismo ou por falta de opção, muitos estudantes acabam por não conhecer a prática extensionista e, tampouco, aceitar um olhar divergente. Outro aspecto que deve ser considerado é apontar a extensão universitária como a terceira missão da universidade. Qual a justificativa para ser a terceira? Ou seria a extensão universitária alguma espécie de nuvem que vaga sobre o ensino e a pes- 
quisa, em alguns dias, se aproximando mais do ensino e, em outros, da pesquisa? A resposta está na necessidade que a universidade tem de enfrentar novos desafios provenientes de sua relação com a sociedade. Isso implica institucionalizar a extensão universitária em cada universidade como essencial para o funcionamento institucional e a formação cidadã. A universidade pública brasileira tem como sua primeira missão produzir conhecimento necessário para auxiliar a sociedade na solução de problemas urgentes e emergentes. Decorre dessa premissa a estreita relação com as atividades realizadas em conjunto com diferentes segmentos da sociedade. No entanto, não se pode estabelecer para a extensão universitária uma missão apartada do todo. Loidi, ${ }^{1}$ em discurso recente, afirmou que

para las universidades constituye um desafio multiplicar su papel como instituciones de conocimiento, aumentando la calidad, cantidad y pertinência de la investigación cientifica y el desarrollo tecnológico que ellas realizan e integrándose mejor com los restantes acores del sistema, com el propósito de contribuir a um mayor impacto económico-social em el processo de desarrollo (2018, p. 12).

É importante defender que as universidades devem considerar como parte de sua ação formativa as contribuições provenientes dos diferentes setores da sociedade, incluindo movimentos sociais e coletivos representativos de segmentos organizados. Assim será possível atualizar e validar uma agenda de compromissos com a sociedade. O conceito de extensão, definido pelo Fórum Nacional de Pró-Reitores das Instituições Públicas de Educação Superior Brasileiras (Forproex), defende a necessidade de "um currículo dinâmico, flexível e transformador" (FORPROEX, 2012, p. 42), capaz de permitir um impulso na democratização do conhecimento. Para Rodriguez, "vale decir, aproximar el saber especificado a la cidadania para empoderarla" (2016, p. 22). Significa que a meta 12.7 do PNE, que prevê a inclusão de créditos realizados em programas e projetos de extensão, precisa se tornar realidade nas universidades. É provável que esse seja, no momento, o maior desafio das universidades. $\mathrm{O}$ contato com as diversas realidades, com as diferenças, com outras perspectivas e mesmo com a crítica é aspecto essencial das formações profissional e cidadã. Há, porém, um viés recorrente na formação universitária enquanto local de produção de conhecimento: a visão de que o único conhecimento que tem valor é aquele produzido no interior das instituições de educação superior. É essa distorção que afasta os estudantes da extensão, em que as atividades são mais complexas e exigem um olhar para o "outro".

O grande desafio que se coloca para que a relação universidade-sociedade seja linear é encontrar motivações docentes e discentes para atividades que não sejam apenas dentro de salas e laboratórios - uma vez que todos estão com muita pressa de cumprir a carga horária exigida -, mas que permitam também a ampliação des- 
ses espaços. A atuação em programas, projetos, territórios é um passo importante para a mudança de perspectiva. Embora seja rígida a estrutura dos currículos dos cursos de graduação, a maioria das universidades brasileiras oferece inúmeras atividades - muitas com auxílio financeiro - que possibilitam aos estudantes realizar tarefas fora dos currículos (para além de salas e laboratórios) que dão outro "brilho" para a formação. Mas o caminho ainda exige vigilância, conforme a política de extensão do Forproex:

o ranço conservador e elitista, presente nas estruturas de algumas Universidades ou departamentos acadêmicos, e a falta de recursos financeiros e organizacionais, entre outros problemas, têm colocado limites importantes para a implantação e implementação desses institutos legais no âmbito das Universidades Públicas. Muitas vezes, verifica-se a normatização da creditação curricular em ações de Extensão, mas restrições em sua implementação. O mesmo descompasso é verificado quanto à inserção de ações extensionistas nos planos de ascensão funcional e nos critérios de pontuação em concursos e à consideração dessas atividades na alocação de vagas docentes. Nesses aspectos, também em algumas Universidades ou departamentos, o preceito constitucional e a legislação referida à Extensão universitária não têm tido qualquer efeito sobre a vida acadêmica (2012, p. 38).

Essa contradição tem pelo menos três componentes reais e cada vez mais perigosos: os currículos fechados em que os estudantes necessitam cumprir uma carga horária estruturada em créditos de disciplinas profissionalizantes, sendo muitos obrigatórios e poucos eletivos; o acomodamento tanto docente quanto discente; e a própria estrutura universitária que se coloca distante do cotidiano, dos movimentos sociais, das demandas gerais da sociedade, com uma rigidez ancorada na burocracia e nos pequenos poderes internos inerentes a todos os órgãos públicos. É mais fácil assistir a uma aula em salas e laboratórios sem questionamentos do que confrontar o aprendizado com a realidade, como novos saberes.

$\mathrm{O}$ discurso persistente de que a universidade, especialmente a universidade pública, deve ser neutra enfraquece não apenas a presença institucional na sociedade, mas também a própria formação oferecida. Não alterar os currículos é uma decorrência dessa visão de neutralidade e de profissionalização. Uma instituição que tem como missão produzir conhecimento e formar cidadãos profissionais competentes, para atuar na sociedade, não pode se colocar na condição de neutralidade, quando a sociedade exige posicionamentos e necessita de novas propostas curriculares para sair do lugar de escola profissionalizante. O maior ou o melhor desempenho das universidades na América Latina está totalmente vinculado ao maior ou ao menor grau de relacionamento entre elas e os demais setores da sociedade. $\mathrm{O}$ não comprometimento com questões sociais graves, sejam da arte, da cultura ou da ciência, gera um distanciamento entre a universidade, uma instituição social e com função pública, e a sociedade, que, em última instância, mantém a universidade 
como local de formação e de construção da cidadania. A dificuldade em propor alternativas, apontar para agendas futuras só faz da universidade um lugar que " $f a z$ mais do mesmo". É evidente que a universidade precisa (re)visitar seus processos de pesquisa e de ensino, valorizando os saberes do senso comum, que como prega o Forproex devem ser "confrontados criticamente com o próprio saber científico, comprometendo a comunidade acadêmica com as demandas sociais e com o impacto de suas ações transformadoras em relação a tais demandas" (2006, p. 16).

A transformação está na gênese das atividades universitárias, especialmente da extensão, que carrega uma visão de mundo construída no contexto acadêmico que transforma e, se transforma, reforma e se reforma constantemente. A universidade não pode deixar de ver nem de ouvir as diferentes demandas da sociedade. Talvez seja possível dizer que a transformação é a essência da extensão. Nessa perspectiva, cabe recorrer a Darcy Ribeiro:

Cumpre perguntar: pode a Universidade converter-se em um instrumento de mudança intencional de nossas sociedades? A rigor, devemos responder que não, já que as classes dominantes farão todo o possível para impedi-lo. Entretanto, as estruturas de poder não são nunca tão homogêneas e coerentes que consigam impor a vontade das classes dirigentes, a menos que a própria Universidade se faça cúmplice delas. Nos dois casos, no da Universidade voltada à renovação necessária e no da Universidade a reboque, a situação será sempre conflitante. No primeiro caso, dados os tumultos provocados pelos interessados em manter o status quo, verão na Universidade seu principal inimigo. No segundo caso, a universidade será convulsionada pela juventude rebelada contra uma instituição que atraiçoa seus ideais. A opção como se vê não é entre a tranqüilidade e o tumulto, mas entre duas ordens de tensão. Cabe ressaltar, entretanto, que os conflitos ativos da primeira ordem de tensões permitem à Universidade exercer, ao menos, o papel de última instituição oficial onde o povo e a nação podem propor-se um projeto próprio de desenvolvimento autônomo e auto-sustentado (1991, p. 22).

Ouso dizer que a extensão é transformadora quando articula o "fazer" da sala de aula, leia-se ensino com pesquisa, e leva este acúmulo para a sociedade da qual recebe contribuições, mudanças, novos olhares e, até mesmo, críticas, trazendo novo aprendizado para o interior da universidade. De que outra forma pode haver um diálogo franco entre duas visões de mundo, duas porções da mesma sociedade, indivisíveis, é verdade, apesar de usualmente diferenciarmos a comunidade acadêmica do "público em geral"? Quando foi lançada no Brasil a rede Objetivos de Desenvolvimento Sustentável Universidades (ODS Univerisdades), ${ }^{2}$ o acordado entre os proponentes foi "fortalecer atividades de ensino, pesquisa e extensão que promovam o desenvolvimento sustentável, em linha com a Agenda 2030" (ONU BRASIL, 2015, não paginado). A rede visa a: estimular a criação de uma cultura institucional que contemple educar para a cidadania econômica, ambiental, cultural e socialmente responsável; articular a realização de atividades interinstitu- 
cionais; promover ações para a troca de experiências; divulgar as ações realizadas pelas instituições por diversos canais de comunicação; promover a discussão dos fundamentos políticos, ideológicos, teóricos e educativos dos ODS; atuar como ponto de consulta e apoio às instituições comprometidas com a implementação dos ODS; promover a interlocução entre as instituições e o Programa das Nações Unidas para o Desenvolvimento (PNUD); promover a interlocução entre as instituições e os órgãos governamentais e não governamentais; criar uma rede de especialistas para a implementação dos ODS no país. A pauta da rede está diretamente relacionada à política nacional de extensão universitária e à política de extensão de cada instituição. $^{3}$

Uma das diretrizes da extensão universitária, que está nos documentos do Forproex, se refere a "impacto e transformação social": ela reafirma a extensão universitária como o mecanismo pelo qual se estabelece a inter-relação da universidade com os outros setores da sociedade, com vistas a uma atuação transformadora, voltada para os interesses e necessidades da maioria da população, e propiciadora dos desenvolvimentos social e regional e de aprimoramento das políticas públicas. A expectativa do Forproex com essa diretriz é que a extensão universitária contribua para o processo de (re)construção da nação, uma comunidade de destino, ou de (re)construção da pólis, a comunidade política. Nesse sentido, a diretriz de “impacto e transformação social” imprime à extensão universitária um caráter essencialmente político.

Com essa diretriz, espera-se configurar nas ações extensionistas as seguintes características: (i) privilegiamento de questões sobre as quais atuar, sem desconsideração da complexidade e da diversidade da realidade social; (ii) abrangência, de forma que a ação, ou um conjunto de ações, possa ser suficiente para oferecer contribuições relevantes para a transformação da área, do setor ou da comunidade em que incide; (iii) efetividade na solução do problema. Cabe lembrar que a efetividade de qualquer tipo de intervenção social depende do grau de racionalidade que se imprime à sua formulação, sem perder de vista os valores e princípios que a sustentam, de forma a permitir sua gestão eficiente e sua avaliação, seja a de seu processo de implementação (monitoramento), seja a de seus resultados e impactos sociais.

A extensão é o lugar da alteridade por excelência. A partir dela, a universidade realiza o reconhecimento da diversidade sociocultural e etnicorracial e permite a construção e o estabelecimento dos compromissos necessários à leitura do mundo. Ao atuar nas dimensões estéticas e culturais, a extensão universitária tensiona o ensino e atualiza a pesquisa. Esse movimento nos convoca não só a pensar o lugar da extensão na formação cidadã dos envolvidos, como também a reconhecer seu 
papel real e seu objetivo na estrutura da universidade no cumprimento daquela que pode ser uma de suas tarefas mais generosas e instigantes: a de ser o local de formação, contribuição e promoção de propostas para melhoria da vida. No interior das universidades, há um questionamento, tornado público, que provoca: "prá que serve o teu conhecimento?", e no seu exterior há uma necessidade latente de profissionais com outras competências, que vão além da técnica, que contribuam na promoção do desenvolvimento da sociedade em todas as suas dimensões.

A prática extensionista que antes se resumia a uma atividade militante de professores, técnicos e alunos, realizada nos finais de semana e sem recurso financeiro ou operacional, hoje trilha caminhos que extrapolam as suas fronteiras e tensionam o interior de cada uma de nossas universidades, configurando o que, em muitos casos, gera duas universidades: uma que permanece fechada sobre si mesma e outra que se articula com a comunidade, que se movimenta, se cria e se recria todos os dias. É nesse cenário que saltam aos olhos os desafios que estão colocados para a extensão universitária praticada nas universidades públicas brasileiras e para a universidade latino-americana como um todo.

É importante ter clareza de que não é apenas sobre a sociedade que se almeja produzir impacto e transformação com a extensão universitária. A própria universidade pública, enquanto parte da sociedade, também deve sofrer impacto, ser transformada. O alcance desses objetivos - impacto e transformação da sociedade e da universidade -, de forma a lograr o desenvolvimento nacional no sentido que a política de extensão propugna, é potencializado nas ações que se orientam pelas diretrizes de interação dialógica, interdisciplinaridade e interprofissionalidade e, por fim, indissociabilidade entre ensino, pesquisa e extensão. Com esse escopo, as ações de extensão universitária surgem como instrumentos capazes de sustar as consequências perversas do neoliberalismo, em especial, a mercantilização das atividades universitárias, a alienação cultural e todas as mazelas que as acompanham. A extensão universitária representa a troca de necessidades e benefícios entre a universidade e a sociedade. Ambos são beneficiários por meio de projetos, convenções e reuniões, melhorando a qualidade de vida na região em que a universidade atua.

No entanto, entre o que se prega e o que se pratica, há uma distância marcada por dificuldades operacionais, preconceitos e temores que envolvem a manutenção do status quo. Senão, vejamos: quais dificuldades se impõem para que a relação entre a universidade e a sociedade se torne mais horizontal? Como pode a sociedade em seus diferentes graus de representação influir nos conteúdos ou projetos gestados no interior da universidade? Qual é a contribuição da universidade para a constituição da cidadania? Talvez precisemos pensar um pouco sobre a forma como 
se dá e qual a qualidade da interação universidade-sociedade. Castro vai direto ao ponto:

No caso da extensão o que percebemos é que ela produz conhecimento a partir da experiência e assim tem uma capacidade de narrar sobre o seu fazer. O conhecimento narrativo não fecha, ele deixa sempre aberto ao final para a possibilidade de se criar outros finais ou se iniciar outros processos. Assim, a forma de produção da narrativa não pretende ser verdadeira objetivamente, mas ser também subjetiva. Além disto, o que se verifica na extensão é um fazer que sempre pressupõe a presença de um outro que não é somente o aluno ou o professor, mas um ouvinte $(2009$, p. 3$)$.

Vale dizer que se comprova que a universidade, a partir de suas atividades de extensão, influencia e é influenciada pelos seus interlocutores. Não significa que, ao configurar quais são as tarefas da extensão universitária, se desresponsabilize o ensino e a pesquisa de seus compromissos com a sociedade. Assim, Severino se expressa:

[...] a universidade, como instituição da esfera educacional, sofre de processo crônico de corrosão interna, deteriorando-se continuamente e comprometendo sua própria eficácia, tornando-se pouco fecunda no atingimento de seus objetivos, consagrados pela tradição e reiterados pela retórica dominante (2002, p. 120).

Nesse caso, há que se abrir espaço para desconstrução de preconceitos históricos e extrair da extensão o que ela nos proporciona de melhor: a possibilidade de conhecimento e compreensão de realidades e comportamentos, a partir de vivências diferenciadas, ainda timidamente presentes em ações educacionais de um modo geral. Não há dúvida nenhuma de que, considerando toda a importância da pesquisa e do ensino, realizar ações que envolvam outros interlocutores, que não apenas o professor e o aluno, agrega valor, embora exija um esforço maior dos envolvidos.

\section{Apontamentos para uma agenda futura}

Ao se apontar para o futuro, é importante retomar a necessidade de incorporação da extensão universitária nos currículos de graduação, atendendo a meta 12.7 do PNE, o que exige posicionamentos imediatos das universidades. As mudanças decorrentes dessa tomada de decisão impactam na formação e na atuação de docentes e discentes, inovam currículos, fortalecem relações entre universidades e sociedade. $O$ que parece ser uma simples resolução acadêmica tem um poder enorme de inovação na formação dos futuros profissionais. Dentro desse verdadeiro "cardápio de desafios" que se impõe para a extensão universitária, está a Agenda 2030: é o momento de repactuar a política de extensão de cada universidade ${ }^{4}$ verificando quanto e como está alinhada com os 17 ODS apresentados pela Organização das 
Nações Unidas (ONU). Como forte componente de políticas públicas com metas a serem cumpridas para melhorar a vida do (e no) planeta, a Agenda 2030 encontra nos programas e projetos de extensão um amparo significativo. Os ODS apontam para a necessidade de acabar com a pobreza e com a fome, melhorando a nutrição, garantindo a segurança alimentar e o bem-estar para todos em todas as idades. Todos reconhecem que esses são temas de muitas atividades de extensão que envolvem diferentes grupos sociais.

O desdobramento de cada um dos 17 ODS aponta para um grande envolvimento das universidades, o que é decorrência do complexo debate registrado no marco da Conferência Regional de Educação Superior (Cres) 2018 e dos Cem anos da Reforma de Córdoba. O último ano nas universidades latino-americanas e caribenhas gerou uma série de questionamentos que se refere à centralidade da educação superior diante das profundas desigualdades existentes em nossa sociedade, das relações de poder e das dificuldades de gestão. Os novos tempos mostram que a sociedade está perpassada por complexas demandas sobre as quais a universidade pode se debruçar não para apontar soluções imediatas, mas para contribuir na busca de melhores alternativas, realizar novas reflexões, como é o caso do ODS 5, que trata da igualdade de gênero e do empoderamento das mulheres. Ao se efetuar um levantamento nas universidades brasileiras, comprova-se o grande número de programas e projetos de extensão envolvendo mulheres na geração de renda, liderança e qualidade de vida.

Outros pontos considerados na Agenda 2030 que integram linhas de atuação da extensão universitária se referem à gestão sustentável da água, a medidas para combater as mudanças do clima e seus impactos, a conservação e uso sustentável dos oceanos e dos mares. Em resumo, os desafios e cenários da extensão universitária são enormes. Cabe a cada instituição escolher o caminho que deseja seguir, que pode ser aquele que é marcado por um estreito vínculo com a sociedade, avançando e trocando experiências, e que pode ser outro, talvez menos árduo, mas certamente menos necessário para todos.

\section{Notas}

1 José Ramón Saborido Loidi é ministro da educação superior de Cuba e fez o discurso de abertura do $11^{\circ}$ Congresso Internacional de Educação Superior, em Havana, em 12 de fevereiro de 2018.

2 Disponível em: <http://www.redeodsuniversidades.ueg.br/conteudo/12207_o_que_e_a_redey>. Acesso em: 10 mar. 2018.

3 A Universidade Federal do Rio Grande do Sul teve política de extensão aprovada pelo conselho universitário em 2012.

4 A Política de Extensão da Universidade Federal do Rio Grande do Sul aprovada pelo conselho universitário em 2012 aponta para alguns dos ODS. 


\section{Referências}

BRASIL. Constituição da República Federativa do Brasil. Brasília, DF: Senado, 1988.

. Decreto n⿳⺈ 6.495 , de 30 de junho de 2008. Institui o Programa de Extensão universitária - PROEXT. Diário oficial, 01 de julho de 2008.

Lei de Diretrizes e Bases da Educação Nacional (LDB). Lei $n^{\circ} 9.394$ 20, de dezembro de 1996. Estabelece as diretrizes e bases da educação nacional. Legislação Federal e Marginália, 1996.

. Lei $n^{\circ} 13.005$, de 25 de junho de 2014. Aprova o Plano Nacional de Educação e dá outras providências. Legislação Federal e Marginália, 2014.

Plano Nacional de Educação (PNE). Lei $n^{\circ}$ 10.172, de 09 de janeiro de 2001. Aprova o Plano Nacional de Educação e dá outras providências. Legislação Federal e Marginália, 2001.

CASTRO, Luciana Maria Cerqueira. A universidade, a extensão universitária e a produção de conhecimentos emancipadores. 2009. Projeto de Tese (Doutorado em Saúde Pública) - Instituto de Medicina Social, UERJ, Rio de Janeiro, 2009.

FREIRE, Paulo. Pedagogia da autonomia: saberes necessários à prática educativa. 6. ed. Rio de Janeiro: Paz e Terra, 1997.

FORPROEX. Indissociabilidade ensino-pesquisa-extensão e a flexibilização curricular: uma visão da extensão. Brasília: Editora UNB, 2006.

Política Nacional de Extensão universitária. Porto Alegre: UFRGS, 2012.

LOIDI, José Ramón Saborido. La Universidad y la agenda 2030 de desarrollo sostenible em el centenário de la reforma universitária de Córdoba. Visión desde Cuba. Discurso de abertura do 11ํㅡㄹ Congresso Internacional de Educação Superior. Havana, Cuba, 12 de fevereiro de 2018.

ONU BRASIL. Objetivos de desenvolvimento sustentável. Agenda 2030. 2015. Disponível em: $<$ http://www.redeodsuniversidades.ueg.br/conteudo/12207_o_que_e_a_redey>. Acesso em: 10 mar. 2018.

RIBEIRO, Darcy. A universidade necessária. 5. ed. Rio de Janeiro: Paz e Terra, 1991.

RODRIGUEZ, Sergio González. La terceira misión de las universidades: politica de vinculación con el médio. Santiago: Universidad Santiago de Chile, 2016.

SEVERINO, Antônio Joaquim. Educação e universidade: conhecimento e construção da cidadania. Revista Interface - Comunic, Saúde, Educ, Botucatu, SP, v. 6, n. 10, p. 117-124, fev. 2002. 